\title{
Overlapping and Distinct Brain Regions Associated with the Anxiolytic Effects of Chlordiazepoxide and Chronic Fluoxetine
}

\author{
Anita J Bechtholt', Rita J Valentino ${ }^{3}$ and Irwin Lucki* ${ }^{1,2}$ \\ 'Department of Psychiatry, University of Pennsylvania, Philadelphia, PA, USA; ²Department of Pharmacology, University of Pennsylvania, \\ Philadelphia, PA, USA; ${ }^{3}$ Department of Anesthesiology and Critical Care Medicine, The Children's Hospital of Philadelphia, Philadelphia, PA, USA
}

\begin{abstract}
Little is known about the sites of action for the behavioral effects of chronic antidepressants. The novelty-induced hypophagia (NIH) test is one of few animal behavioral tests sensitive to acute benzodiazepines and chronic antidepressants. The goals of these experiments were to examine patterns of brain activation associated with the behavioral response to novelty and identify regions that could regulate the anxiolytic effects of acute benzodiazepine and chronic antidepressant treatments, measured using the $\mathrm{NIH}$ test. In the first experiment, rats were treated acutely with the anxiolytic, chlordiazepoxide ( 2.5 or $5 \mathrm{mg} / \mathrm{kg}$, i.p.). In separate experiments, animals were implanted with osmotic minipumps delivering vehicle or fluoxetine ( 5 or $20 \mathrm{mg} / \mathrm{kg}$ per day s.c.) for 3 or 28 days. NIH was assessed by giving animals access to a familiar palatable food in a novel environment. Associated brain areas were identified using c-fos immunohistochemistry. $\mathrm{NIH}$ was mitigated by acute chlordiazepoxide and chronic fluoxetine. Both drugs reversed novelty-induced changes in c-fos expression in the lateral division of the posterolateral part of the bed nucleus of the stria terminalis (STLP), cingulate cortex (Cg), and dorsal field CA2 of the hippocampus (dCA2). Chronic fluoxetine additionally increased c-fos expression in the anterior nucleus accumbens $(\mathrm{aAcb})$ and the piriform cortex (Pir). The effects of the drugs on c-fos expression in many regions correlated with anxiolytic efficacy. These findings identified brain regions where the effects of chronic antidepressants and benzodiazepines may converge to produce anxiolytic activity, as well as distinct sites of action for the two classes of drugs.

Neuropsychopharmacology (2008) 33, 21 I7-2130; doi: I 0.1038/sj.npp. I 301616; published online 7 November 2007
\end{abstract}

Keywords: novelty; hypophagia; serotonin; fluoxetine; chlordiazepoxide; anxiety

\section{INTRODUCTION}

Although antidepressants are frequently prescribed to treat both depression and anxiety, it is not clear why there is a delay of up to several weeks before they produce a significant clinical response (Gelenberg and Chesen, 2000). Understanding the mechanisms underlying this delayed response has been hindered by a lack of animal behavioral tests that are exclusively sensitive to chronic antidepressant treatment. In contrast to many measures of antidepressant efficacy, suppression of feeding induced by exposure to novelty is reversed by antidepressants from several classes following chronic, but not acute, treatment (Bodnoff et al, 1988; Dulawa and Hen, 2005). Thus, one key observation of clinical treatment mirrored by the novelty-induced hypophagia (NIH) test is that antidepressants are only effective at reducing the inhibitory effects of novelty when they are given repeatedly, for weeks. Elucidating the mechanisms and circuitry underlying this delay in response is critical to

*Correspondence: Dr I Lucki, Department of Psychiatry, University of Pennsylvania, 2204 Translational Research Labs, 125 South 31 St., Philadelphia, PA 19104-3403, USA, Tel: +215 573 3305, Fax: + 215 5732149 , E-mail: lucki@pharm.med.upenn.edu

Received I 4 May 2007; accepted 8 September 2007 hasten the development of more expedient treatments for anxiety and depression.

A second key characteristic of the NIH test is that it is one of the few rodent behavioral tests that demonstrates the ability of chronic antidepressant treatments to reduce anxiety. While anxiety can be a prominent component of clinical depression, chronic antidepressant treatments are often prescribed to treat anxiety disorders such as generalized anxiety disorder (Dolnak, 2006; Nutt et al, 2006), panic disorder (Dolnak, 2006) and obsessive-compulsive disorder (Blier et al, 2006). In the NIH test, the anxiety-provoking effects of novelty can be reduced by either acute administration of benzodiazepines or by chronic antidepressants (Dulawa et al, 2004; Merali et al, 2003; Sanders and Shekhar, 1995). There are few other tests of anxiety that reliably demonstrate the antianxiety effects of chronic antidepressants (Borsini et al, 2002). Greater understanding of this test has important implications for understanding how antidepressants work to, in the least, treat anxiety disorders and, possibly, to treat depression.

Although neuroadaptations resulting from repeated antidepressant treatments have been reported for different brain regions and targets, the critical neural circuitry that mediates repeated antidepressant treatment efficacy remains unknown. The goal of the present experiments was to 
identify neural circuitry underlying anxiolytic and chronic antidepressant treatments using the NIH test. To begin mapping the circuitry of the NIH paradigm, these experiments used c-fos mapping to identify specific cell populations that are recruited in response to novelty and contrasted brain areas of overlap or dissociation between effective treatment with the benzodiazepine chlordiazepoxide and chronic administration of the antidepressant fluoxetine.

\section{MATERIALS AND METHODS}

\section{Animals}

These studies used 108 male Sprague-Dawley rats obtained from Charles River Laboratories Inc. weighing 225-250 g on arrival and housed two per polycarbonate cage. Home cages were lined with bedding material. Animals were not food deprived during any part of the experiment.

\section{Novelty-Induced Hypophagia}

Animals were trained to consume a palatable food in the home cage for 8 days. This time was required to reach stable intakes and latencies to begin eating (Bechtholt et al, 2007). Ninety minutes prior to daily feeding sessions an opaque Plexiglas divider was inserted into the home cage, separating the two animals. Each rat was individually presented with 8-10g of graham cracker crumbs (Nabisco) for $15 \mathrm{~min}$. Novelty-induced suppression of feeding was assessed by giving individual animals access to the familiar graham cracker crumbs in a novel environment. The novel environment consisted of a polycarbonate cage of the same dimensions as the home cage $(48 \mathrm{~L} \times 26 \mathrm{~W} \times 20 \mathrm{H} \mathrm{cm})$ that was brightly lit and had a wire, rather than bedding lined floor. Latency to begin eating (s) and food consumed in both the home and novel cage were measured. An additional group of vehicle-treated animals sacrificed after a home cage test was included in each of the experiments to detect effects of exposure to novelty. Animals were sacrificed $90 \mathrm{~min}$ after the start of the final test.

\section{Drug Treatments}

Acute chlordiazepoxide treatment. On the day after training, animals were subjected to a final home cage feeding session that served as the home cage test. On the following day, animals were injected with chlordiazepoxide $(0.0,2.5,5.0 \mathrm{mg} / \mathrm{kg}$ i.p. $)$ or saline $(0.9 \%) 30 \mathrm{~min}$ prior to the novel cage test.

Chronic fluoxetine treatment. After the training period, animals were implanted with osmotic minipumps delivering fluoxetine $(0.0,5.0,20.0 \mathrm{mg} / \mathrm{kg}$ per day) or vehicle. The animals were then left undisturbed in the colony for 23 days. To reacquaint animals with the palatable food and test procedures, animals were subjected to five additional home cage feeding sessions, with the last day being the home cage test. The response to novelty was determined $24 \mathrm{~h}$ later. Thus, animals were sacrificed after 28 days of fluoxetine treatment.
Subchronic fluoxetine treatment. The effects of treatment with fluoxetine for 28 days were compared with a group of rats that received treatment with fluoxetine for only 3 days. This period of treatment allowed behavioral assessment after full onset of the drug infusion from the minipump but was not long enough to produce neuroadaptive changes. Immediately following training, animals were implanted with osmotic minipumps delivering fluoxetine $(0.0,5.0$, $20.0 \mathrm{mg} / \mathrm{kg}$ per day). Home cage and novel cage tests were conducted 48 and $72 \mathrm{~h}$ after implantation, respectively. Animals were thus sacrificed after 3 days of fluoxetine treatment.

\section{Drugs}

Fluoxetine $\mathrm{HCl}$ (ANAWA Biomedical Services \& Products, Zurich, Switzerland) was dissolved in $100 \%$ ethanol by slight heating and diluted with sterile distilled and deionized water to a final ethanol concentration of $50 \%$ for delivery by osmotic minipump. Chlordiazepoxide $\mathrm{HCl}$ (Sigma-Aldrich Co., St Louis, MO) and sodium pentobarbital (Sigma-Aldrich Co., St Louis, MO) were dissolved in sterile distilled and deionized water. Doses were determined by the base weight.

\section{Implantation of Osmotic Minipumps}

Animals were anesthetized (sodium pentobarbital; $50 \mathrm{mg} / \mathrm{kg}$ i.p.) and implanted with Alzet osmotic minipumps (DURECT Corporation, Cupertino, CA) delivering fluoxetine or vehicle inserted into a subcutaneous pocket made along the dorsolateral abdomen. The incision above the scapulae was closed with wound clips and treated with betadine.

\section{Immunohistochemistry for c-Fos}

Immunohistochemistry for c-fos was conducted as previously described with the exception of the primary antibody (Roche et al, 2003). Ninety min after the start of the final test rats were perfused ( $4 \%$ paraformaldehyde) and brains were stored in fixative overnight $\left(4^{\circ} \mathrm{C}\right)$ and then a sucrose solution until saturated. Nonserial $30 \mu \mathrm{m}$ coronal sections were cut on a cryostat and incubated in rabbit antic-fos antisera (Abcam Inc., Cambridge, MA) for 3 days at $4{ }^{\circ} \mathrm{C}$ at a dilution of $1: 1000$. Sections were then incubated in biotinylated donkey anti-rabbit antiserum $(1: 200$; Jackson Labs, West Grove, PA) for $90 \mathrm{~min}$, followed by avidin-biotin complex $(1: 600$; ABC Elite Kit, Vector Labs, Burlingame, CA) for $90 \mathrm{~min}$ at room temperature. Sections were immersed in $0.02 \%$ 3,3'-diaminobenzidine- $4 \mathrm{HCl}$ (DAB; Sigma-Aldrich Co., St Louis, MO) containing 0.01\% $\mathrm{H}_{2} \mathrm{O}_{2}$ in phosphate buffer for $10-15 \mathrm{~min}$ for a brown reaction product that was terminated by rinses in phosphate buffer. Sections were mounted and photomicrographs were taken at $\times 20$ magnification (Leica Microsystems, Wetzlar, Germany). The number of labeled cells was counted for each rat and brain area using Image J (National Institutes of Health-public domain) software in the three nonserial sections closest to those shown in Figure 1. The average of the three sections was recorded as the number of c-fos positive cells for each animal and region. 


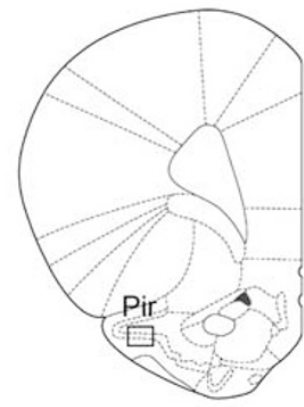

$+3.25$

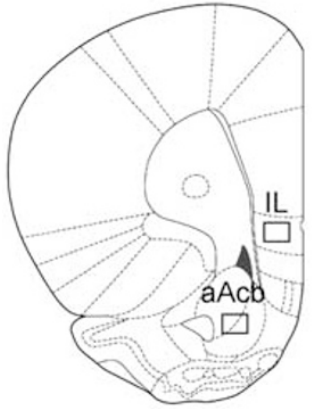

$+2.76$

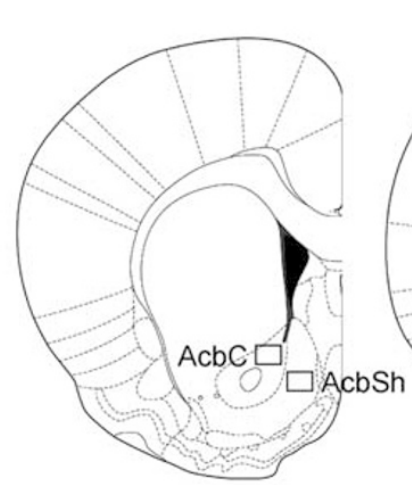

$+1.68$

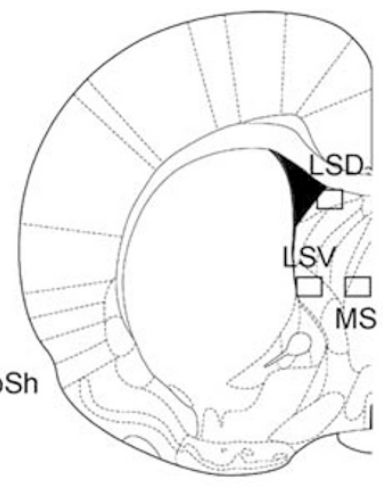

$+0.36$

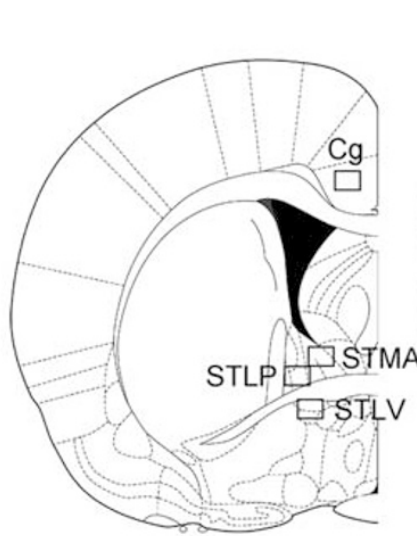

$-0.12$

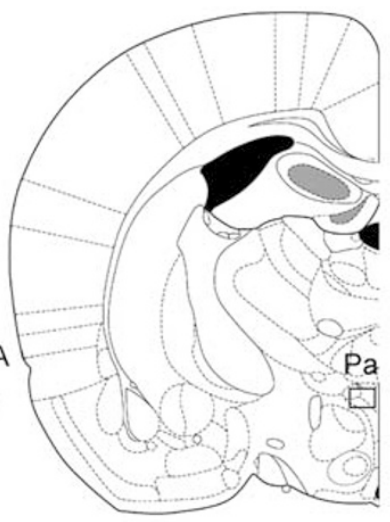

$-1.80$

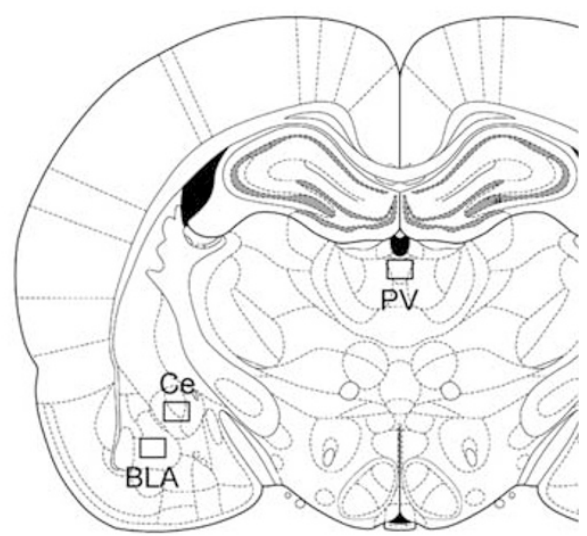

$-2.76$

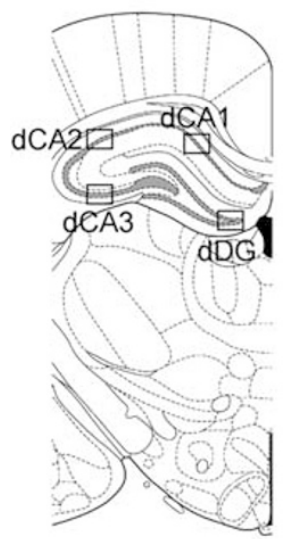

$-3.12$

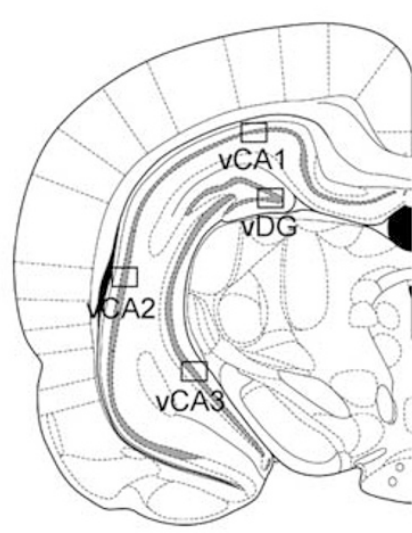

$-4.92$

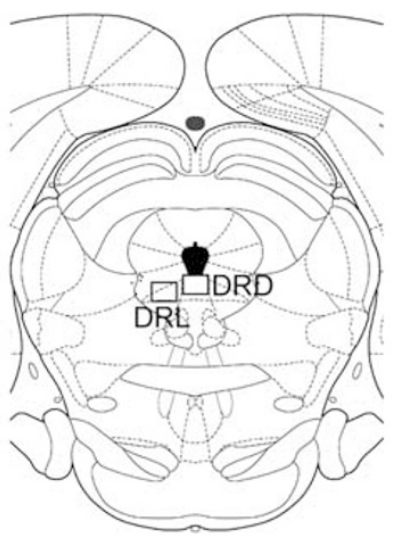

$-7.32$

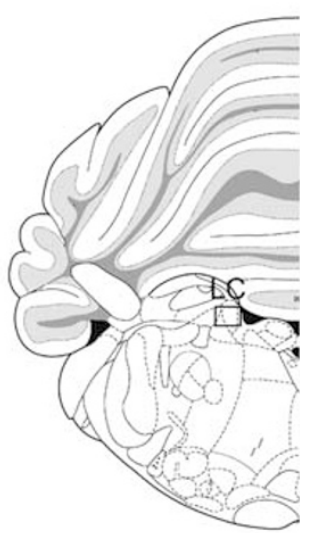

$-9.84$

Figure I Localization of the 27 areas counted for c-fos immunoreactivity indicated on atlas representations of the rat brain (Figures I0, I2, 19, 30, 34, 48, 56, 59, 74, 94, II 5 in Paxinos and Watson (2004)). Abbreviations are defined in Tables I-3.

\section{Statistical Analysis}

Behavioral data were analyzed using mixed two-way analysis of variance (ANOVAs) with the within-subjects independent variable of environment (home, novel) and the between-subjects independent variable of dose. Follow-up comparisons to significant interactions were conducted on both raw data and on difference scores by one-way ANOVA and Fisher's protected least significant difference test. Difference scores were calculated by subtracting the values measured in the home cage from those measured in the novel cage. c-Fos data were analyzed using one-way ANOVAs for each brain area within each experiment. To determine the relationship between the number of c-fos positive cells after exposure to the novel environment and the behavioral outcomes, simple regression analyses were conducted for those brain areas in which significant ANOVAs were obtained. Only the treatment groups exposed to the novel environment were included in these regression analyses (Vehicle Novel Cage, drug dose A Novel Cage, drug dose B Novel Cage). 


\section{RESULTS}

\section{Effects of Acute Chlordiazepoxide on NIH}

Figure 2 (left panels) illustrates that acute chlordiazepoxide treatment substantially reduced the magnitude of NIH, as supported by a significant main effect of environment $(\mathrm{F}(1,27)=73.8, \quad p<0.0001)$ and an environment $\times$ dose interaction $(\mathrm{F}(2,27)=5.7, p<0.001)$ for raw intake values. Follow-up one-way ANOVAs on raw intake values yielded a significant main effect of dose on feeding in the novel cage $(\mathrm{F}(2,27)=4.4, p<0.05)$. Additional follow-up comparisons revealed that animals treated with $5.0 \mathrm{mg} / \mathrm{kg}$ of chlordiazepoxide ate more in the novel cage than vehicle-treated animals $(p<0.01)$ and both doses of chlordiazepoxide induced smaller intake differences compared to vehicle treatment $(2.5 \mathrm{mg} / \mathrm{kg}$ per day, $p<0.05 ; 5.0 \mathrm{mg} / \mathrm{kg}$ per day, $p<0.005)$.

NIH outcomes for latency were generally similar to those of intake but more variable as previously reported (Bechtholt et al, 2007; Dulawa and Hen, 2005). Vehicletreated animals showed increased latencies to feed in the novel environment that were reduced, but not significantly, by acute chlordiazepoxide treatment (Figure 2, right panels). These observations were substantiated by a significant main effect of environment $(F(1,27)=43.0$, $p<0.0001)$ and a nonsignificant environment $\times$ dose interaction, $\mathrm{F}(2,27)=2.0, p=0.16$ for raw latency values.

\section{Effects of Chronic Fluoxetine on NIH}

Figure 3 demonstrates that fluoxetine effectively reduced the suppressive effect of novelty in the NIH test after 28 days of treatment. Vehicle-treated animals displayed a large decrease in food intake in the novel cage compared to the home cage, while fluoxetine treatment mitigated this effect (Figure 3, left panels). These conclusions were supported by significant main effects of environment $(\mathrm{F}(1,18)=40.0$, $p<0.0001)$ and dose $(\mathrm{F}(2,18)=11.7, p<0.0005)$ and a significant environment $\times$ dose interaction $(\mathrm{F}(2,18)=10.6$, $p<0.001)$ for raw intake values. Further, a one-way ANOVA of raw home cage intake values yielded a significant main effect of dose $(F(2,18)=9.2, p<0.005)$. Pairwise comparisons of raw home cage intake values revealed that chronic fluoxetine treatment increased feeding in animals treated with $5.0 \mathrm{mg} / \mathrm{kg}$ per day $(p<0.05)$ of fluoxetine and decreased feeding in animals treated with $20.0 \mathrm{mg} / \mathrm{kg}$ per day $(p<0.05)$ of fluoxetine. Despite these changes in home cage feeding, animals treated with either dose of fluoxetine ate more in the novel cage than vehicle-treated animals $(5 \mathrm{mg} / \mathrm{kg}$ per day, $p<0.001 ; 20 \mathrm{mg} / \mathrm{kg}$ per day, $p<0.001$ ). Additional follow-up comparisons of intake difference scores revealed significantly smaller differences in intake between the home and novel cage in animals treated with either dose of fluoxetine compared to vehicle-treated animals $(5 \mathrm{mg} / \mathrm{kg}$ per day, $p<0.05 ; 20 \mathrm{mg} / \mathrm{kg}$ per day, $p<0.001)$.

Chronic fluoxetine treatment diminished the ability of novelty to increase the latency to feed (Figure 3, right panels). A two-way ANOVA for raw latency values demonstrated significant main effects of environment $(\mathrm{F}(1,18)=73.8, \quad p<0.0001)$ and dose $(\mathrm{F}(2,18)=13.0$, $p<0.0005)$ and a significant environment $\times$ dose interaction $(\mathrm{F}(2,18)=14.5, p<0.0005)$. A one-way ANOVA of raw latency values yielded a significant effect of dose in the novel cage $(\mathrm{F}(2,18)=13.8, p<0.0005)$, but not home cage latency. Pairwise comparisons revealed that chronic fluoxetine treatment decreased the latency to feed relative to vehicle treatment $(p<0.001)$. Follow-up comparisons on latency difference scores revealed that the effect of novelty
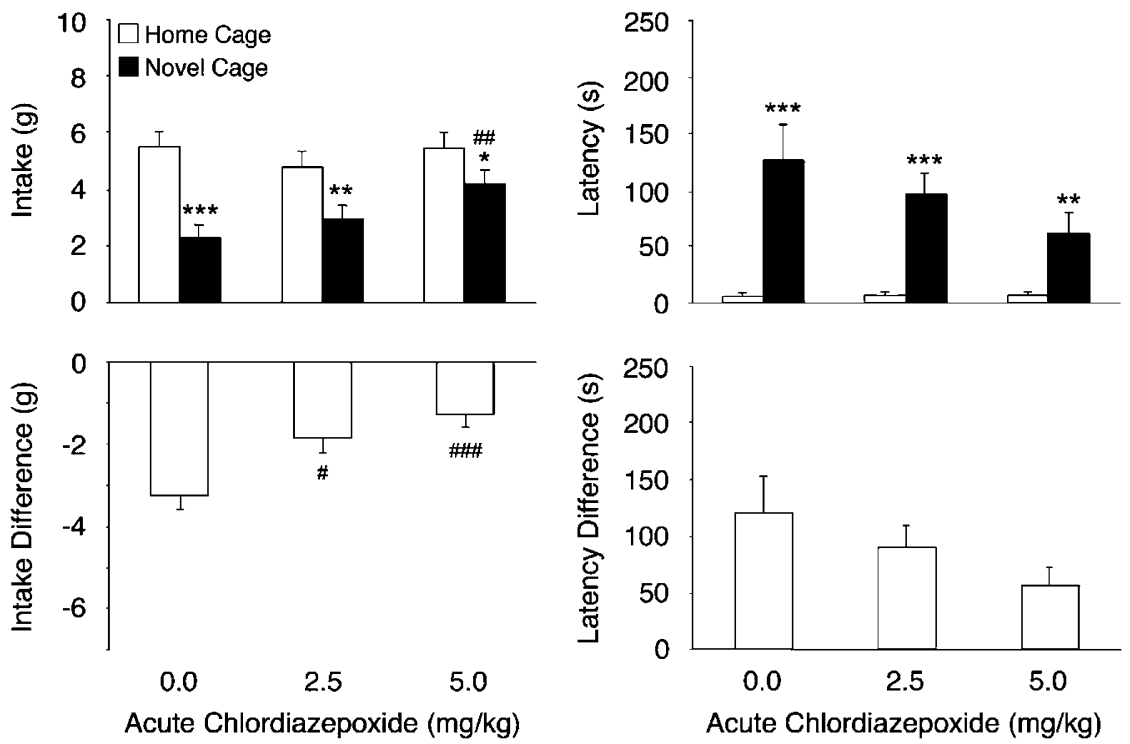

Figure 2 Effect of acute chlordiazepoxide $(2.5$ or $5.0 \mathrm{mg} / \mathrm{kg}$ ) on $\mathrm{NIH}(n=10$ per group). Each bar indicates the mean ( $\pm \mathrm{SEM})$ absolute raw graham cracker intake values in grams (top left), raw latency to begin eating values in seconds (top right), the difference in intake (bottom left) or difference in latency (bottom right) between the home and novel cage (novel cage intake-home cage intake). Follow-up comparisons revealed that animals treated acutely with chlordiazepoxide ate more graham cracker crumbs in the novel environment than vehicle-treated animals. In contrast, chlordiazepoxide did not significantly alter the increased latency for initiating feeding produced by novelty. *Difference between home and novel cage intakes within the same treatment group. \#Different from group treated with vehicle for the same dependent variable. One symbol $p<0.05$, two symbols $p<0.01$, three symbols $p<0.001$. 

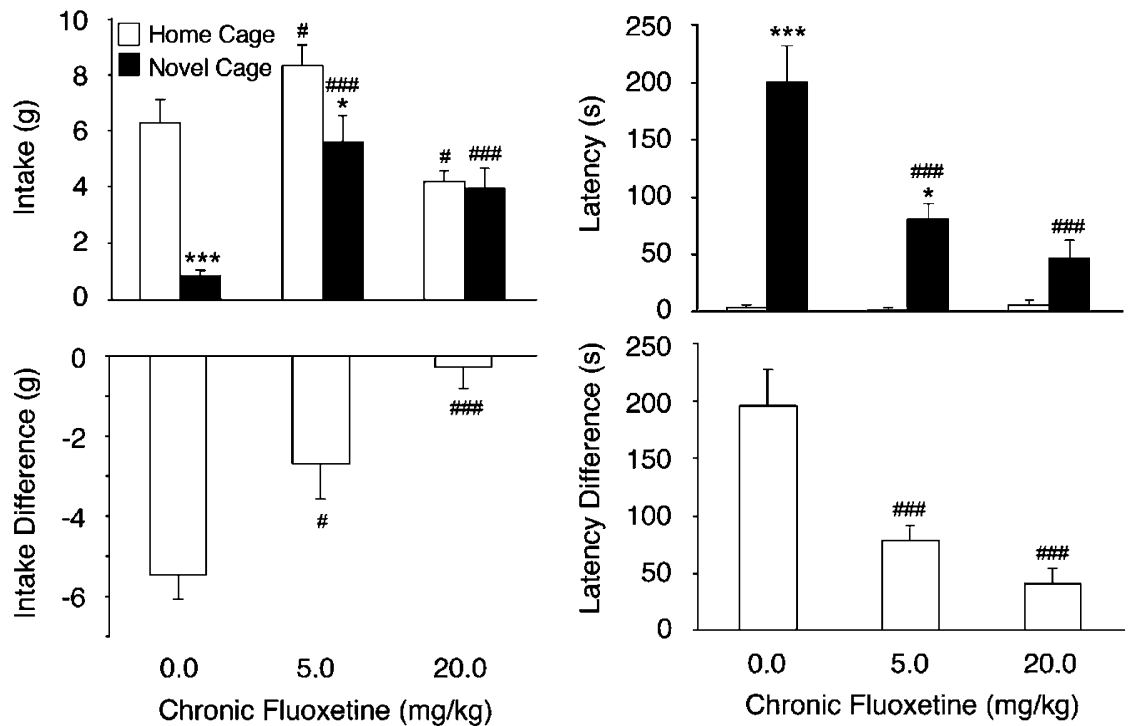

Figure 3 Effect of chronic fluoxetine ( 5 or $20 \mathrm{mg} / \mathrm{kg}$ per day given for 28 days) on $\mathrm{NIH}$ ( $n=6-8$ per group). Each bar indicates the mean ( \pm SEM) absolute raw graham cracker intake values in grams (top left), raw latency to begin eating values in seconds (top right), the difference in intake (bottom left) or difference in latency (bottom right) between the home and novel cage (novel cage intake-home cage intake). Follow-up comparisons revealed that animals treated chronically with fluoxetine ate more graham cracker crumbs and initiated feeding in the novel environment more rapidly than vehicle-treated animals. *Difference between home and novel cage intakes within the same treatment group. "Different from vehicle treated for the same dependent variable. One symbol $p<0.05$, three symbols $p<0.001$.

on latency to begin feeding was decreased by chronic fluoxetine treatment compared to vehicle treatment $(5 \mathrm{mg} /$ $\mathrm{kg}$ per day, $p<0.001 ; 20 \mathrm{mg} / \mathrm{kg}$ per day, $p<0.0001)$.

\section{Effects of Subchronic Fluoxetine on NIH}

In contrast to chronic administration, subchronic administration of fluoxetine did not alter the magnitude of NIH. A two-way ANOVA for raw intake values detected a significant main effect of environment $(\mathrm{F}(1,27)=103.1$, $p<0.0001)$ but no significant environment $\times$ dose interaction (Figure 4, left panels). Similarly, the two-way ANOVA for raw latency values demonstrated a significant main effect of environment $(F(1,27)=72.8, p<0.0001)$ but no interaction $(\mathrm{F}(2,27)=1.7, p=0.195)$; Figure 4 , right panels). Further, in order to determine whether surgery $72 \mathrm{~h}$ prior to behavioral testing could have influenced intakes, intake data from the final training day were compared by two-way mixed ANOVA to those of the final home test, which occurred $48 \mathrm{~h}$ after surgery. No significant effects of time, treatment, or their interaction were detected. That is, mean intakes in the home cage after surgery (mean \pm SEM: vehicle $=5.0 \pm 0.53$; Flx $5.0 \mathrm{mg} / \mathrm{kg}=4.6 \pm 0.68$; Flx $20.0 \mathrm{mg} /$ $\mathrm{kg}=3.8 \pm 0.72)$ were not significantly different from those prior to surgery (vehicle $=4.9 \pm 0.45 ; \quad$ Flx $5.0 \mathrm{mg}$ / $\mathrm{kg}=5.2 \pm 0.91 ;$ Flx $20.0 \mathrm{mg} / \mathrm{kg}=5.6 \pm 0.54)$.

\section{c-Fos Expression Associated with NIH}

Figures 5 and 6 demonstrate typical c-fos photomicrographs. Tables 1-3 show the mean number of $\mathrm{c}$-fos positive cells for each treatment group, $p$-values for the one-way ANOVAs and abbreviations for all of the examined brain regions. The general effects of exposure to novelty were replicated across the three separate experiments. Thus, in the absence of drug treatment, novelty increased the number of c-fos profiles in the $\mathrm{Cg}$, Pir, and $\mathrm{dCA} 2$ and tended to decrease the number of $\mathrm{c}$-fos profiles within the lateral division of the posterolateral part of the STLP across experiments.

Acute chlordiazepoxide reversed the effects of novelty on c-fos expression in the STLP (Figure 5, top panels), Cg, Pir, dCA2. Additionally, novelty increased c-fos expression in the vHC and LSV in vehicle controls for this experiment and these effects were reversed by chlordiazepoxide. Significant one-way ANOVAs for the number of c-fos-positive profiles were observed for effects among the acute chlordiazepoxide treatment groups in the $\operatorname{STLP}(\mathrm{F}(3,36)=4.0, p<0.01), \mathrm{Cg}$ $(\mathrm{F}(3,36)=3.3, p<0.05)$, Pir $(\mathrm{F}(3,36)=4.4, p<0.01), \mathrm{dCA} 2$ $(\mathrm{F}(3,36)=2.9, p<0.51), \quad \mathrm{dCA} 1 \quad(\mathrm{~F}(3,36)=4.10, p<0.01)$, $\operatorname{vCA} 2(\mathrm{~F}(3,36)=3.1, p<0.05), \operatorname{LSD}(\mathrm{F}(3,36)=4.1, p<0.01)$, and $\operatorname{LSV}(\mathrm{F}(3,36)=3.3, p<0.05)($ Table 1$)$.

Like chlordiazepoxide, chronic fluoxetine reversed novelty-induced changes in c-fos expression in the STLP (Figure 5, bottom panels), Cg and dCA2. In addition this treatment had effects that were distinct from those of chlordiazepoxide, including an increase in c-fos expression in the aAcb (Figure 6, top panels) and in the Pir. Novelty did not alter c-fos expression in the lateral septum or ventral hippocampus of vehicle-treated rats in this experiment. Significant effects among the chronic fluoxetine treatment groups were detected for the $\mathrm{aAcb}(\mathrm{F}(3,21)=5.7, p<0.005)$, STLP, $(\mathrm{F}(3,21)=3.8, p<0.05), \mathrm{Cg}(\mathrm{F}(3,22)=5.6, p<0.005)$, Pir $(\mathrm{F}(3,22)=7.0, \quad p<0.005)$, and $\mathrm{dCA} 2 \quad(\mathrm{~F}(3,23)=3.8$, $p<0.05$ ) (Table 2).

The c-fos counts for subchronic fluoxetine treatment in these five regions are shown in Table 3. One-way ANOVAs yielded significant effects of the subchronic fluoxetine treatment group in the $\operatorname{Cg}(\mathrm{F}(3,36)=4.1, \quad p<0.01), \quad \operatorname{Pir} \quad(\mathrm{F}(3,36)=5.6$, $p<0.005)$, and $\mathrm{dCA} 2(\mathrm{~F}(3,36)=3.1, p<0.05)$. 

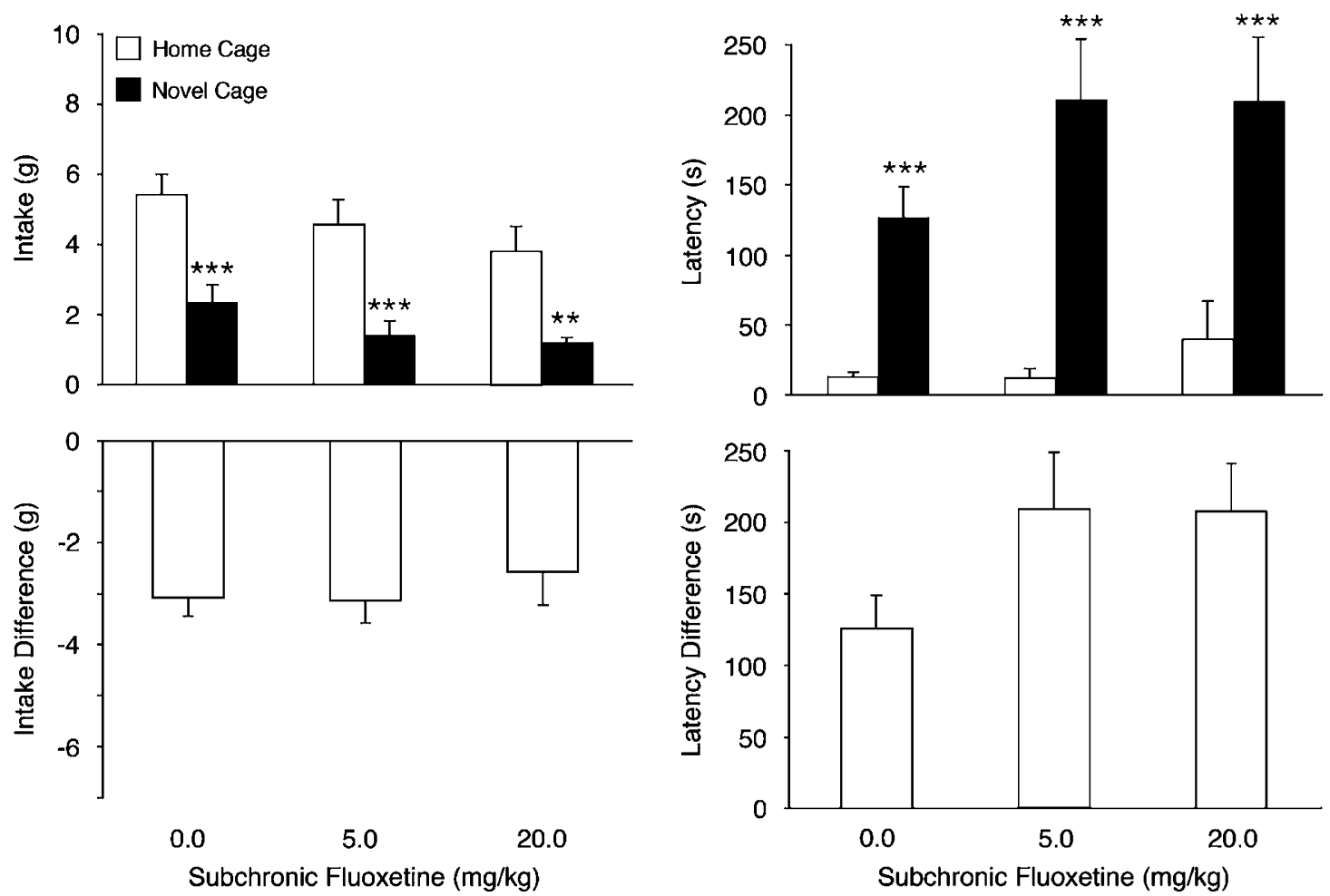

Figure 4 Effect of subchronic fluoxetine ( 5 or $20 \mathrm{mg} / \mathrm{kg}$ per day given for 3 days) on $\mathrm{NIH}$ ( $n=10$ per group). Each bar indicates the mean ( \pm SEM) absolute raw graham cracker intake values in grams (top left), raw latency to begin eating values in seconds (top right), the difference in intake (bottom left) or difference in latency (bottom right) between the home and novel cage (novel cage intake-home cage intake). Subchronic fluoxetine treatment (5 or $20 \mathrm{mg} / \mathrm{kg}$ per day) did not inhibit the suppression of intake or increased latency to initiate feeding produced by novelty. * Difference between home and novel cage intakes within the same treatment group. Two symbols $p<0.01$, three symbols $p<0.00$ I.

Vehicle Home Cage

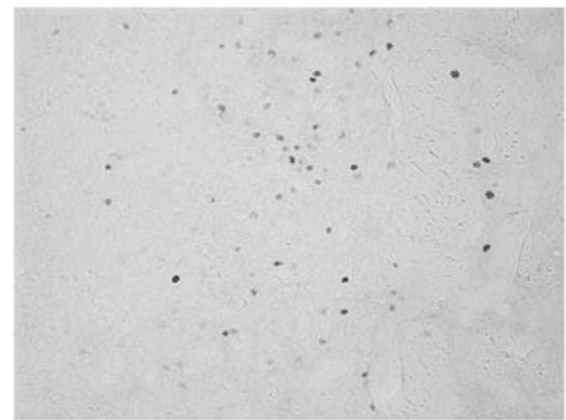

Vehicle Home Cage

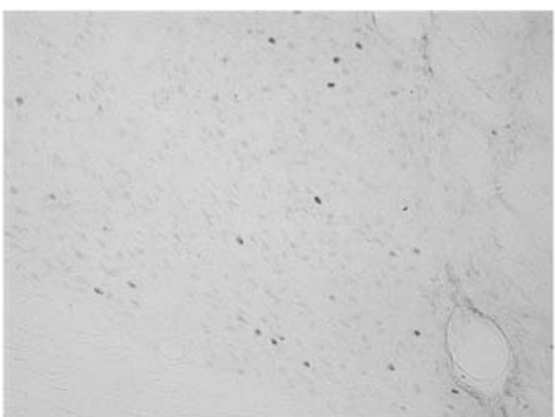

Vehicle Novel Cage

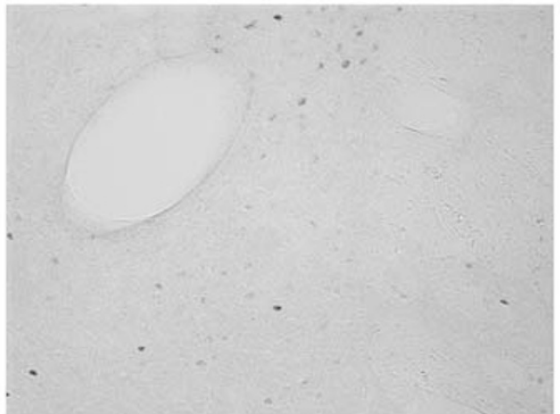

Vehicle Novel Cage

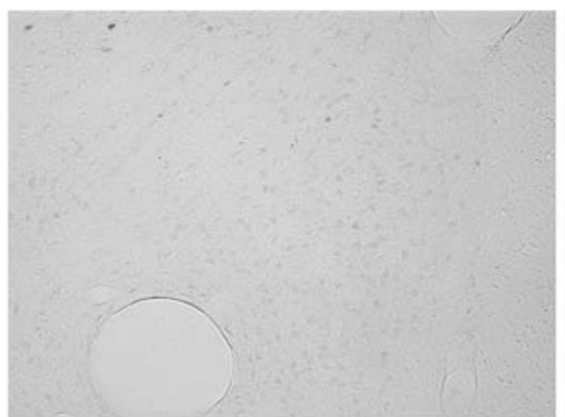

Chlordiazepoxide $5 \mathrm{mg} / \mathrm{kg}$ Novel Cage

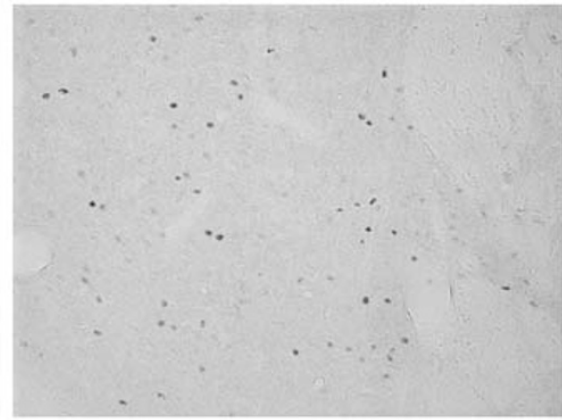

Fluoxetine $20 \mathrm{mg} / \mathrm{kg}$ Novel Cage

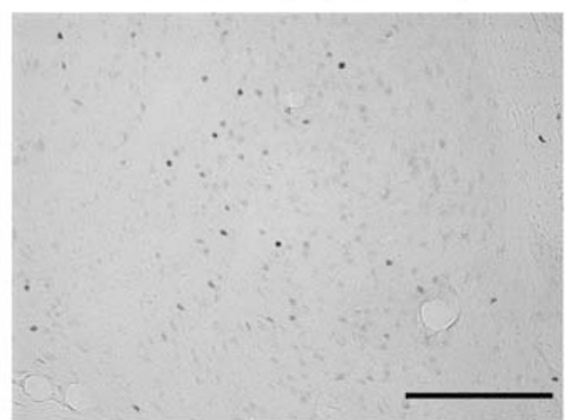

Figure 5 Example photomicrographs of c-fos staining in the STLP from animals treated with vehicle and tested in the home cage, treated with vehicle and tested in the novel cage and treated with $5 \mathrm{mg} / \mathrm{kg}$ chlordiazepoxide and tested in the novel cage are shown from the acute chlordiazepoxide experiment (top panels). Sections from animals treated with vehicle and tested in the home cage, treated with vehicle and tested in the novel cage and treated with $20 \mathrm{mg} / \mathrm{kg}$ chronic fluoxetine and tested in the novel cage are shown from the chronic fluoxetine experiment (bottom panels). The top of the images is dorsal, while the left is medial. Bar indicates $150 \mu \mathrm{m}$. 

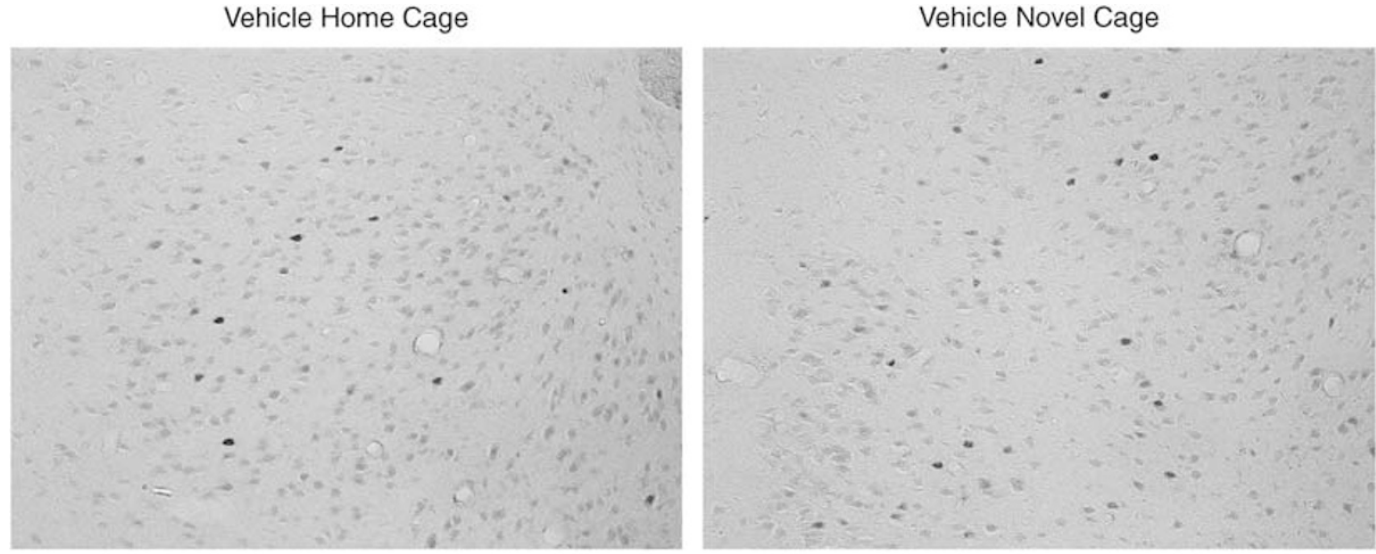

Fluoxetine $5 \mathrm{mg} / \mathrm{kg}$ Novel Cage

Fluoxetine $20 \mathrm{mg} / \mathrm{kg}$ Novel Cage
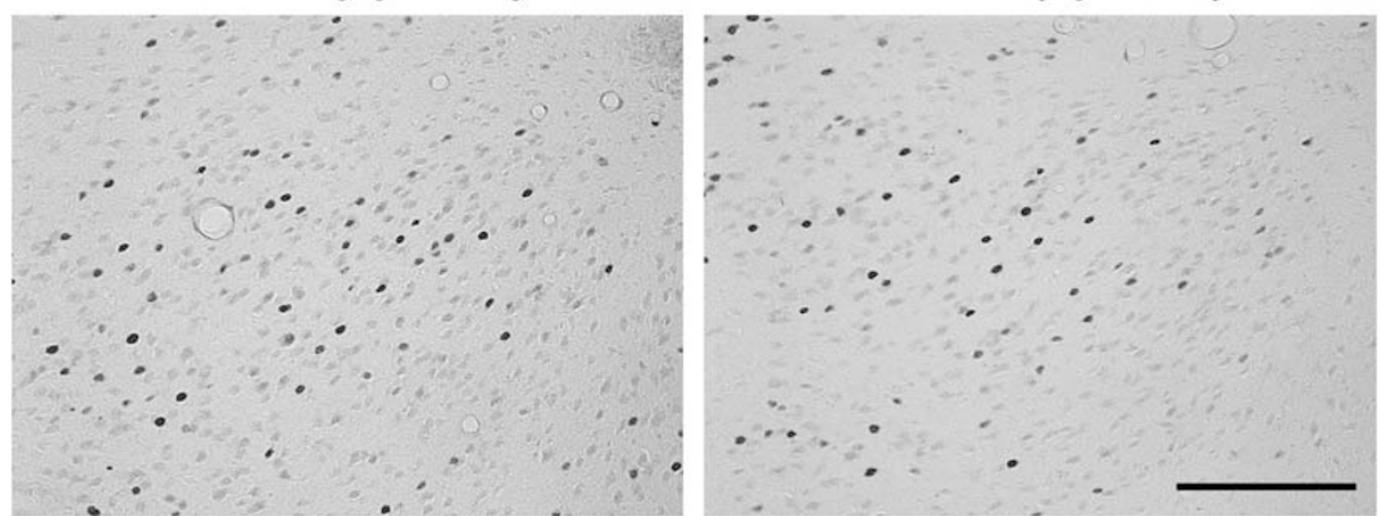

Figure 6 Example photomicrographs of c-fos staining in the aAcb from animals treated with vehicle and tested in the home cage (top left), treated with vehicle and tested in the novel cage (top right), treated with $5 \mathrm{mg} / \mathrm{kg}$ chronic fluoxetine and tested in the novel cage (bottom left) and treated with $20 \mathrm{mg} / \mathrm{kg}$ chronic fluoxetine and tested in the novel cage (bottom right) are shown from the chronic fluoxetine experiment. The top of the images is dorsal, while the left is medial. Bar indicates $150 \mu \mathrm{m}$.

\section{Correlation of Behavior with Neuronal Activation}

Regression analyses were used to identify brain sites in which changes in neuronal activation may be associated with NIH or its pharmacological attenuation. Regression coefficients for the relationship between the number of $\mathrm{c}$-fos positive cells and each behavioral outcome are shown in Table 4. An anxiolytic effect produced by chlordiazepoxide, expressed by increased novel cage intake, was correlated with decreased c-fos expression in the $\mathrm{Cg}(r=0.36, p<0.05)$ and greater expression of $c$-fos in the STLP $(r=0.39$, $p<0.05)$. No other significant regression analyses were observed.

Chronic fluoxetine treatment increased food intake in the novel cage and was associated with fewer $c$-fos positive cells in the $\mathrm{Cg}(r=-0.49, p<0.05)$. Likewise, smaller differences in intake between the home and novel cages were predictive of fewer c-fos positive profiles in the $\mathrm{Cg}(r=-0.67$, $p<0.005)$ and the dCA2 $(r=-0.44, p<0.05)$. Among the chronic fluoxetine treatment groups, shorter novel cage latencies were predictive of a greater number of $\mathrm{c}$-fos positive cells in the aAcb $(r=-0.51, p<0.05)$, STLP $(r=-0.48, p<0.05)$, and the Pir $(r=-0.45, p<0.05)$. This relationship was also demonstrated for the difference in latency between the home and novel cages for the aAcb $(r=-0.50, p<0.05)$.
No significant relationships were observed between the number of c-fos positive cells counted in any brain area and novel cage outcomes for animals in the subchronic fluoxetine experiment.

\section{DISCUSSION}

These findings are the first demonstration that regional patterns of brain activity during the performance of the NIH test correlate with anxiolytic behavioral outcomes evoked by both chronic antidepressant drug treatments and traditional benzodiazepine treatments. Despite the widespread prescription of antidepressants for anxiety disorders, there is little understanding of the neural substrates that contribute to the anxiolytic effects that emerge gradually from chronic antidepressant treatment. Here, regional activation patterns reveal areas where the response to novelty is suppressed or activation is engaged to counteract the effects of novelty. These convergent and discordant findings between drug classes provide information about similar and distinct mechanisms that may regulate anxiolytic effects.

The NIH test provided a structure for identifying the neural circuitry germane to anxiolytic treatments because it is a behavior that is changed by treatment with 
Table I Expression of c-Fos After Exposure to Novelty and Modification by Acute Chlordiazepoxide (Cdp) Treatment

\begin{tabular}{|c|c|c|c|c|c|c|c|}
\hline \multirow{2}{*}{ Brain area } & \multirow{2}{*}{ Subdivision } & \multirow{2}{*}{ Abbreviation } & \multicolumn{4}{|c|}{ c-Fos positive cells } & \multirow{2}{*}{$p$-value } \\
\hline & & & $\begin{array}{l}\text { Home cage } \\
\text { vehicle }\end{array}$ & $\begin{array}{l}\text { Novel cage } \\
\text { vehicle }\end{array}$ & $\begin{array}{l}\text { Novel cage } \\
2.5 \mathrm{mg} / \mathrm{kg} \text { Cdp }\end{array}$ & $\begin{array}{l}\text { Novel cage } \\
5.0 \mathrm{mg} / \mathrm{kg} \text { Cdp }\end{array}$ & \\
\hline \multirow[t]{3}{*}{ Accumbens nuclei } & Anterior & aAcb & $9.17 \pm 1.74$ & $13.47 \pm 2.85$ & $13.67 \pm 2.48$ & $12.53 \pm 3.24$ & 0.602 \\
\hline & Core & $A c b C$ & $13.23 \pm 3.26$ & $11.60 \pm 2.67$ & $7.77 \pm 1.53$ & $11.37 \pm 1.88$ & 0.450 \\
\hline & Shell & AcbSh & $9.93 \pm 1.53$ & $11.93 \pm 2.53$ & $6.60 \pm 0.69$ & $12.13 \pm 1.27$ & 0.081 \\
\hline \multirow[t]{2}{*}{ Amygdaloid nuclei } & Basolateral & $\mathrm{BL}$ & $5.43 \pm 1.67$ & $6.80 \pm 1.49$ & $6.57 \pm 1.02$ & $9.43 \pm 1.62$ & 0.283 \\
\hline & Central & $\mathrm{Ce}$ & $8.30 \pm 2.02$ & $5.97 \pm 1.17$ & $8.97 \pm 2.20$ & $12.43 \pm 2.32$ & 0.160 \\
\hline \multirow[t]{3}{*}{$\begin{array}{l}\text { Bed nucleus of the stria } \\
\text { terminalis }\end{array}$} & $\begin{array}{l}\text { Lateral division, posterolateral } \\
\text { part }\end{array}$ & STLP & $13.00 \pm 2.27$ & $7.20 \pm 0.96^{\mathrm{a}}$ & $7.37 \pm 1.13^{\mathrm{a}, \mathrm{b}}$ & $12.53 \pm 1.64^{c}$ & $0.015^{d}$ \\
\hline & Medial division, anterior part & STMA & $13.10 \pm 1.69$ & $13.83 \pm 2.13$ & $10.77 \pm 2.03$ & $10.87 \pm 2.19$ & 0.621 \\
\hline & Medial division, ventral part & STMV & $19.60 \pm 2.35$ & $|4.13 \pm 2.8|$ & $15.63 \pm 2.83$ & $|4.27 \pm 2.4|$ & 0.423 \\
\hline \multirow[t]{3}{*}{ Cortex } & Cingulate & $\mathrm{Cg}$ & $7.07 \pm 0.99$ & $14.90 \pm 3.34^{\mathrm{a}}$ & $7.13 \pm 1.18^{c}$ & $9.27 \pm 1.79$ & $0.033^{d}$ \\
\hline & Infralimbic & $\mathrm{IL}$ & $25.23 \pm 3.92$ & $24.83 \pm 2.31$ & $21.93 \pm 3.76$ & $33.87 \pm 5.97$ & 0.230 \\
\hline & Piriform & Pir & $15.23 \pm 4.26$ & $37.03 \pm 6.44^{\mathrm{a}}$ & $16.00 \pm 3.22^{c}$ & $24.63 \pm 4.81$ & $0.010^{d}$ \\
\hline \multirow[t]{2}{*}{ Dorsal raphe nuclei } & Dorsal part & DRD & $14.00 \pm 3.46$ & $10.13 \pm 2.6 \mid$ & $8.70 \pm 1.92$ & $13.57 \pm 1.47$ & 0.364 \\
\hline & Lateral part & $\mathrm{DRL}$ & $11.37 \pm 2.90$ & $8.83 \pm 2.36$ & $9.33 \pm 2.50$ & $10.73 \pm 1.81$ & 0.870 \\
\hline \multirow[t]{8}{*}{ Hippocampus } & Dorsal field CAI & dCAl & $2.70 \pm 0.79$ & $4.47 \pm 0.95$ & $2.18 \pm 0.57$ & $4.10 \pm 1.60$ & 0.366 \\
\hline & Dorsal field CA2 & $\mathrm{dCA} 2$ & $4.53 \pm 1.32$ & $8.77 \pm 1.53^{\mathrm{a}}$ & $3.67 \pm 0.85^{c}$ & $5.67 \pm 1.44$ & $0.049^{d}$ \\
\hline & Dorsal field CA3 & $\mathrm{dCA} 3$ & $3.17 \pm 0.73$ & $3.80 \pm 2.26$ & $2.67 \pm 0.58$ & $2.37 \pm 0.53$ & 0.429 \\
\hline & Dorsal dentate gyrus & $\mathrm{dDG}$ & $10.77 \pm 2.50$ & $10.43 \pm 1.89$ & $6.50 \pm 1.20$ & $11.30 \pm 1.91$ & 0.290 \\
\hline & Ventral field CAI & $v C A I$ & $3.07 \pm 1.03$ & $8.82 \pm 1.67^{\mathrm{a}}$ & $5.63 \pm 0.77$ & $7.13 \pm 1.21^{\mathrm{a}}$ & $0.014^{d}$ \\
\hline & Ventral field CA2 & $\mathrm{VCA} 2$ & $4.00 \pm 0.88$ & $7.00 \pm 1.17^{\mathrm{a}}$ & $3.55 \pm 0.67^{\mathrm{b}, \mathrm{c}}$ & $6.53 \pm 1.18$ & $0.040^{d}$ \\
\hline & Ventral field CA3 & vCA3 & $2.17 \pm 0.43$ & $2.77 \pm 0.40$ & $1.80 \pm 0.32$ & $2.08 \pm 0.22$ & 0.278 \\
\hline & Ventral dentate gyrus & vDG & $2.43 \pm 0.53$ & $4.20 \pm 0.54$ & $2.80 \pm 0.35$ & $3.30 \pm 0.42$ & 0.060 \\
\hline \multirow[t]{2}{*}{ Lateral septal nuclei } & Dorsal part & LSD & $3.23 \pm 1.05$ & $4.73 \pm 0.88$ & $1.35 \pm 0.53^{c}$ & $1.70 \pm 0.49^{c}$ & $0.014^{d}$ \\
\hline & Ventral part & LSV & $6.93 \pm 0.92$ & $12.73 \pm 1.90^{\mathrm{a}}$ & $6.60 \pm 1.65^{c}$ & $10.83 \pm 1.90$ & $0.030^{d}$ \\
\hline Locus coeruleus & Locus coeruleus & LC & $2.37 \pm 0.51$ & $2.37 \pm 0.54$ & $2.67 \pm 0.48$ & $4.50 \pm 1.11$ & 0.117 \\
\hline Medial septum & Medial septum & MS & $3.12 \pm 0.58$ & $6.00 \pm 1.16$ & $3.13 \pm 0.91$ & $5.43 \pm 1.30$ & 0.110 \\
\hline $\begin{array}{l}\text { Paraventricular } \\
\text { hypothalamic nucleus }\end{array}$ & $\begin{array}{l}\text { Paraventricular hypothalamic } \\
\text { nucleus }\end{array}$ & $\mathrm{Pa}$ & $22.97 \pm 4.38$ & $21.45 \pm 4.49$ & $30.23 \pm 4.84$ & $13.44 \pm 4.25$ & 0.493 \\
\hline $\begin{array}{l}\text { Paraventricular thalamic } \\
\text { nucleus }\end{array}$ & Paraventricular thalamic nucleus & PV & $22.60 \pm 3.40$ & $20.90 \pm 5.51$ & $20.57 \pm 2.98$ & $23.33 \pm 2.91$ & 0.948 \\
\hline
\end{tabular}

$n=10$ per group.

asignificantly different from Home Cage Vehicle group.

SSignificantly different from Novel Cage $5.0 \mathrm{mg} / \mathrm{kg}$ Cdp group.

'Significantly different from Novel Cage Vehicle group.

dSignificant one-way ANOVA. 
Table 2 Expression of c-Fos After Exposure to Novelty and Modification by Chronic Fluoxetine (Flx) Treatment

\begin{tabular}{|c|c|c|c|c|c|c|c|}
\hline \multirow{2}{*}{ Brain area } & \multirow{2}{*}{ Subdivision } & \multirow{2}{*}{ Abbreviation } & \multicolumn{4}{|c|}{ c-Fos positive cells } & \multirow{2}{*}{$p$-value } \\
\hline & & & $\begin{array}{l}\text { Home cage } \\
\text { vehicle }\end{array}$ & $\begin{array}{l}\text { Novel cage } \\
\text { vehicle }\end{array}$ & $\begin{array}{l}\text { Novel cage } \\
5.0 \mathrm{mg} / \mathrm{kg} \mathrm{Flx}\end{array}$ & $\begin{array}{c}\text { Novel cage } \\
20.0 \mathrm{mg} / \mathrm{kg} \mathrm{Flx}\end{array}$ & \\
\hline \multirow[t]{3}{*}{ Accumbens nuclei } & Anterior & $a A c b$ & $6.86 \pm 2.36$ & $7.57 \pm 2.58$ & $23.74 \pm 5.15^{\mathrm{a}, \mathrm{b}}$ & $20.54 \pm 4.07^{\mathrm{a}, \mathrm{b}}$ & $0.005^{c}$ \\
\hline & Core & AcbC & $3.17 \pm 1.17$ & $2.95 \pm 1.44$ & $0.95 \pm 0.74$ & $1.89 \pm 1.13$ & 0.503 \\
\hline & Shell & AcbSh & $0.86 \pm 0.34$ & $1.00 \pm 0.41$ & $1.52 \pm 0.72$ & $1.50 \pm 0.45$ & 0.711 \\
\hline \multirow[t]{2}{*}{ Amygdaloid nuclei } & Basolateral & $\mathrm{BL}$ & $0.43 \pm 0.14$ & $1.33 \pm 0.80$ & $1.00 \pm 0.29$ & $1.22 \pm 0.59$ & 0.571 \\
\hline & Central & $\mathrm{Ce}$ & $2.40 \pm 0.69$ & $1.44 \pm 0.73$ & $1.36 \pm 0.62$ & $0.72 \pm 0.47$ & 0.321 \\
\hline \multirow[t]{3}{*}{$\begin{array}{l}\text { Bed nucleus of the stria } \\
\text { terminalis }\end{array}$} & $\begin{array}{l}\text { Lateral division, posterolateral } \\
\text { part }\end{array}$ & STLP & $5.94 \pm 1.16$ & $1.67 \pm 0.59^{a}$ & $2.92 \pm 0.83^{\mathrm{a}}$ & $3.25 \pm 1.11$ & $0.026^{c}$ \\
\hline & Medial division, anterior part & STMA & $2.69 \pm 0.82$ & $2.61 \pm 0.62$ & $3.31 \pm 1.23$ & $2.56 \pm 0.70$ & 0.938 \\
\hline & Medial division, ventral part & STMV & $7.25 \pm 2.10$ & $7.00 \pm 2.25$ & $4.31 \pm 1.00$ & $7.17 \pm 3.30$ & 0.686 \\
\hline \multirow[t]{3}{*}{ Cortex } & Cingulate & $\mathrm{Cg}$ & $1.17 \pm 0.35$ & $3.89 \pm 1.05^{\mathrm{a}}$ & $2.10 \pm 0.52^{b}$ & $0.43 \pm 0.13^{b}$ & $0.005^{c}$ \\
\hline & Infralimbic & IL & $1.39 \pm 0.44$ & $1.71 \pm 0.60$ & $4.14 \pm 1.61$ & $2.97 \pm 1.92$ & 0.426 \\
\hline & Piriform & Pir & $3.00 \pm 0.53$ & $7.36 \pm 1.48^{\mathrm{a}}$ & $12.86 \pm 2.32^{\mathrm{a}, \mathrm{b}}$ & $12.17 \pm 2.35^{\mathrm{a}, \mathrm{b}}$ & $0.002^{c}$ \\
\hline \multirow[t]{2}{*}{ Dorsal raphe nuclei } & Dorsal part & DRD & $1.14 \pm 0.62$ & $1.19 \pm 0.54$ & $2.82 \pm 1.06$ & $0.76 \pm 0.35$ & 0.490 \\
\hline & Lateral part & DRL & $2.14 \pm 0.71$ & $3.71 \pm 2.21$ & $3.52 \pm 1.27$ & $2.30 \pm 1.49$ & 0.837 \\
\hline \multirow[t]{8}{*}{ Hippocampus } & Dorsal field CAI & dCAI & $1.00 \pm 0.59$ & $2.17 \pm 0.81$ & $2.57 \pm 1.27$ & $0.28 \pm 0.23$ & 0.236 \\
\hline & Dorsal field CA2 & dCA2 & $1.33 \pm 0.51$ & $4.38 \pm|.3|^{\mathrm{a}}$ & $3.62 \pm 0.96^{\mathrm{d}}$ & $0.61 \pm 0.55^{b}$ & $0.024^{c}$ \\
\hline & Dorsal field CA3 & dCA3 & $0.71 \pm 0.25$ & $1.33 \pm 0.54$ & $1.86 \pm 0.56$ & $0.28 \pm 0.16$ & 0.083 \\
\hline & Dorsal dentate gyrus & $\mathrm{dDG}$ & $2.29 \pm 1.34$ & $1.26 \pm 0.53$ & $1.95 \pm 0.78$ & $0.67 \pm 0.29$ & 0.573 \\
\hline & Ventral field CAI & vCAI & $1.97 \pm 0.67$ & $3.83 \pm 1.48$ & $3.81 \pm 1.71$ & $1.87 \pm 1.27$ & 0.580 \\
\hline & Ventral field CA2 & vCA2 & $1.76 \pm 0.62$ & $2.89 \pm 0.98$ & $1.78 \pm 0.51$ & $2.25 \pm 1.19$ & 0.706 \\
\hline & Ventral field CA3 & vCA3 & $1.33 \pm 0.69$ & $2.64 \pm 0.60$ & $2.28 \pm 0.85$ & $1.42 \pm 0.97$ & 0.423 \\
\hline & Ventral dentate gyrus & vDG & $1.74 \pm 0.38$ & $2.44 \pm 0.74$ & $3.22 \pm 0.93$ & $1.67 \pm 0.67$ & 0.380 \\
\hline \multirow[t]{2}{*}{ Lateral septal nuclei } & Dorsal part & LSD & $1.38 \pm 0.69$ & $1.33 \pm 0.62$ & $2.38 \pm 0.70$ & $1.81 \pm 0.95$ & 0.642 \\
\hline & Ventral part & LSV & $5.92 \pm 1.32$ & $8.10 \pm 3.12$ & $6.14 \pm 2.20$ & $3.00 \pm 1.45$ & 0.467 \\
\hline Locus coeruleus & Locus coeruleus & LC & $0.61 \pm 0.13$ & $0.57 \pm 0.30$ & $0.28 \pm 0.14$ & $0.31 \pm 0.16$ & 0.511 \\
\hline Medial septum & Medial septum & MS & $3.25 \pm 0.79$ & $4.43 \pm 1.11$ & $3.90 \pm 1.01$ & $2.72 \pm 1.26$ & 0.692 \\
\hline $\begin{array}{l}\text { Paraventricular } \\
\text { hypothalamic nucleus }\end{array}$ & $\begin{array}{l}\text { Paraventricular hypothalamic } \\
\text { nucleus }\end{array}$ & $\mathrm{Pa}$ & $7.90 \pm 1.89$ & $7.67 \pm 2.48$ & $7.52 \pm 1.60$ & $4.36 \pm 1.68$ & 0.430 \\
\hline $\begin{array}{l}\text { Paraventricular thalamic } \\
\text { nucleus }\end{array}$ & Paraventricular thalamic nucleus & PV & $5.07 \pm 1.02$ & $5.29 \pm 1.22$ & $6.81 \pm 1.37$ & $4.72 \pm 1.02$ & 0.641 \\
\hline \multicolumn{8}{|c|}{$\begin{array}{l}\text { Vehicle Home cage } n=7-8 \text {; Vehicle Novel Cage } n=6-7 \text {; Nov } \\
\text { aSignificantly different from Home Cage Vehicle group. } \\
\text { bSignificantly different from Novel Cage Vehicle group. } \\
\text { 'Significant one-way ANOVA. } \\
\text { dSignificantly different from Novel Cage } 20.0 \mathrm{mg} / \mathrm{kg} \text { Flx group. }\end{array}$} \\
\hline
\end{tabular}




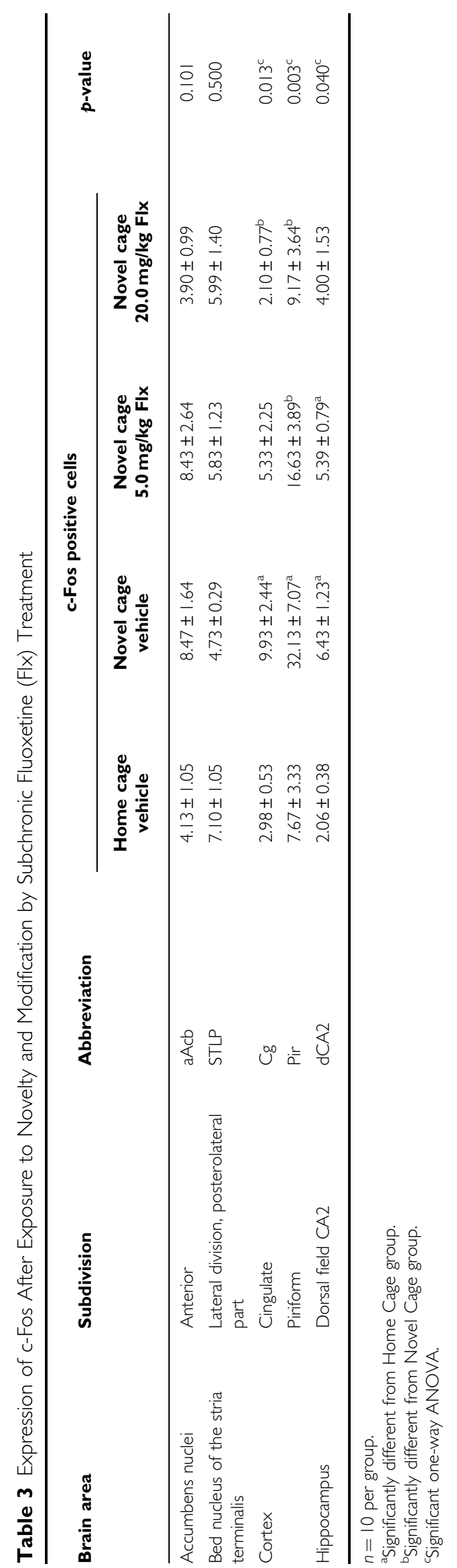

psychotherapeutic treatments that are clinically relevant. Novelty-induced anxiety as evidenced by reduced food intake and increased latency to feed in the novel cage relative to the home cage. Acute chlordiazepoxide or chronic fluoxetine mitigated this anxiety by decreasing the difference in intake between the home and novel cage. Latency score analyses yielded similar results, however, these scores were typically highly variable in this test (Bechtholt et al, 2007; Dulawa and Hen, 2005). Thus, although significant for chronic fluoxetine treatment, only a tendency toward a decrease in novel cage latencies was observed following chlordiazepoxide, which may be due to the sedative effects of this drug. These common anxiolytic outcomes are consistent with numerous previous reports using the novelty-suppressed feeding paradigm and a number of reports using the NIH paradigm and confirm the ability of acute benzodiazepines and chronic antidepressants to increase feeding in the NIH test (for review see Dulawa and Hen, 2005).

Exposure to novelty yielded unique patterns of activation in discrete brain areas. Novelty increased c-fos expression in the dCA2, $\mathrm{Cg}$, and Pir and decreased c-fos expression in the STLP. Similar responses to novelty have been reported previously for the Cg (Stone et al, 2006a, b; Struthers et al, 2005; Wirtshafter, 2005), Pir (Stone et al, 2006a,b) and dCA2 (Wirtshafter, 2005) in other contexts. The patterns of change observed here were consistent across the three experiments, suggesting that these are reliable and meaningful observations. In addition, the effects of anxiolytic treatment and regional c-fos expression were correlated in a number of areas.

The dCA2 was activated in response to novelty, an effect that was normalized by acute chlordiazepoxide or chronic fluoxetine treatment, but may also have been affected by subchronic fluoxetine treatment. However, the c-fos response was significantly correlated only with the anxiolytic effects of chronic fluoxetine treatment. The roles of stress, depression, and antidepressant treatment in the hippocampus have been extensively studied over recent years (Dranovsky and Hen, 2006). In general, this region is vulnerable to the effects of chronic stress by way of neurotoxicity, remodeling of cellular morphology, decreased neurogenesis and reductions of the neurotrophin brain-derived neurotrophic factor (D'Sa and Duman, 2002). Hippocampal volume is decreased in patients with unremitted depression (Sheline et al, 2003) or post-traumatic stress disorder (Bremner, 2006), and this may be improved by successful chronic antidepressant treatment (Bremner and Vermetten, 2004). The present results are in agreement with these many findings and extend them to suggest that specific subregions of the hippocampus may be critical for the anxiolytic effects of chronic antidepressant treatment.

Exposure to novelty activated the $\mathrm{Cg}$ and all three treatments attenuated this effect to some degree. However, the patterns of c-fos expression were significantly correlated only with anxiolytic behavioral outcomes elicited by acute chlordiazepoxide or chronic fluoxetine treatment. Lesions of this nucleus reportedly induce prodepressant behavior in the rodent forced swimming test, while performance on an anxiety-related test, the elevated plus maze, was unchanged (Bissiere et al, 2006). This apparent dissociation between measures of anxiety and depression may be explained by 
Table 4 Regression Coefficients for the Relationship between the Number of c-Fos Positive Cells and Each Behavioral Outcome That Was Altered by Exposure to Novelty

\begin{tabular}{|c|c|c|c|c|c|}
\hline \multirow{2}{*}{ Brain area } & \multirow{2}{*}{ Abbreviation } & \multicolumn{4}{|c|}{ Regression coefficient ( $r$ ) } \\
\hline & & $\begin{array}{l}\text { Novel cage } \\
\text { intake }\end{array}$ & $\begin{array}{l}\text { Intake } \\
\text { difference }\end{array}$ & $\begin{array}{l}\text { Novel cage } \\
\text { latency }\end{array}$ & $\begin{array}{l}\text { Latency } \\
\text { difference }\end{array}$ \\
\hline \multicolumn{6}{|l|}{ Acute chlordiazepoxide } \\
\hline $\begin{array}{l}\text { Bed nucleus of the stria terminalis, } \\
\text { lateral division posterolateral part }\end{array}$ & STLP & $0.39^{\mathrm{a}}$ & 0.28 & -0.26 & -0.25 \\
\hline Piriform cortex & Pir & -0.27 & -0.30 & -0.05 & -0.06 \\
\hline Dorsal field CA2 & $\mathrm{dCA} 2$ & -0.24 & -0.21 & 0.13 & 0.14 \\
\hline Ventral field CAI & VCAI & -0.34 & -0.07 & -0.24 & -0.25 \\
\hline Ventral field CA2 & vCA2 & -0.10 & 0.07 & 0.03 & 0.04 \\
\hline Lateral septal nucleus, dorsal part & LSD & -0.27 & -0.14 & 0.16 & 0.17 \\
\hline $\begin{array}{l}\text { Bed nucleus of the stria terminalis, } \\
\text { lateral division posterolateral part }\end{array}$ & STLP & 0.47 & 0.31 & $-0.48^{\mathrm{a}}$ & -0.47 \\
\hline Cingulate cortex & $\mathrm{Cg}$ & $-0.49^{\mathrm{a}}$ & $-0.67^{\mathrm{a}}$ & 0.37 & 0.37 \\
\hline Piriform cortex & Pir & 0.23 & 0.04 & $-0.45^{\mathrm{a}}$ & -0.43 \\
\hline Dorsal field CA2 & $\mathrm{dCA} 2$ & -0.23 & $-0.44^{\mathrm{a}}$ & 0.29 & 0.31 \\
\hline \multicolumn{6}{|l|}{ Subchronic fluoxetine } \\
\hline Cingulate cortex & $\mathrm{Cg}$ & 0.15 & -0.08 & -0.22 & -0.21 \\
\hline Piriform cortex & Pir & -0.08 & -0.23 & -0.06 & -0.01 \\
\hline Dorsal field CA2 & $\mathrm{dCA} 2$ & 0.16 & -0.08 & -0.25 & -0.19 \\
\hline
\end{tabular}

asignificant regression coefficient.

the general finding that most rodent anxiety tests, including the elevated plus maze, are not sensitive to the anxiolytic effects of antidepressants (Borsini et al, 2002). Although not extensively studied, some human findings suggest that the $\mathrm{Cg}$ is involved in the incidence of phobias (Rauch et al, 1995), social anxiety disorder (Phan et al, 2005), obsessivecompulsive disorder (Rauch et al, 1994), and post-traumatic stress disorder (Rauch et al, 2003). The present findings have striking similarity to imaging studies in depressed patients where overactivation of the $\mathrm{Cg}$ was normalized by successful antidepressant treatments, including chronic fluoxetine treatment (Mayberg et al, 2000) and sleep deprivation ( $\mathrm{Wu}$ et al, 2001). Further, direct inactivation of the $\mathrm{Cg}$ with deep brain stimulation alleviated treatmentresistant depression (Mayberg et al, 2005). Given that the activity of the $\mathrm{Cg}$ has been extensively implicated in psychiatric disorders that are responsive to chronic antidepressant treatment, it is unlikely that the present findings are the result of noncausal drug effects. Perhaps these findings suggest that the $\mathrm{Cg}$ is an important locus for both the acute and chronic effects of fluoxetine. Although it is clear that the ability of fluoxetine to increase serotonin is not sufficient for treatment, it likely contributes to the therapeutic efficacy of chronic treatment, since serotonin depletion can reverse effective treatment by SSRIs of depression and anxiety disorders (for review see Bell et al (2005)). Thus, while changes in c-fos expression in the $\mathrm{Cg}$ were evident after subchronic treatment with the higher dose of fluoxetine, continued administration for a chronic period may be required for elicitation of the associated behavioral effects. Taken together, these findings suggest that the $\mathrm{Cg}$ represents an important point of overlap between the anxiolytic effects of acute benzodiazepines and chronic antidepressants, but may also describe a brain area through which the direct pharmacological effects of antidepressants are changed to produce an anxiolytic outcome.

The Pir was activated by novelty, an effect that was strengthened by chronic fluoxetine treatment and correlated with the latency to begin feeding in the novel cage. In contrast, subchronic fluoxetine reversed the effects of novelty. These findings suggest that this locus may be activated to cope with stressful events, the function of which is enhanced by chronic fluoxetine treatment. This brain region has not been extensively studied with respect to anxiety and depression. However, it has been reported that the Pir was degenerated in the rodent olfactory bulbectomy model of depression (Wang et al, 2007), and that two treatments for depression, chronic fluoxetine treatment (Zhou et al, 2006), and electroconvulsive shock (Sun et al, 
2005), respectively increased the density of serotonin transporter reactive terminals and induced a number of plasticity related genes in this region. The finding that subchronic fluoxetine had opposing effects on c-fos expression in the Pir to both exposure to novelty and chronic fluoxetine treatment may reflect the anxietyprovoking effects of acute fluoxetine reported in humans and many animal anxiety tests (Dulawa and Hen, 2005), including the novelty-suppressed feeding paradigm (Bodnoff et al, 1989), that could not be detected in the present test. Finally, the role of the Pir in the anxiolytic effects of chlordiazepoxide remains unclear because the lowest dose of chlordiazepoxide reversed the effects of novelty, but effects at the highest dose were inconclusive. This pattern of results may be related to the nonspecific sedative effects of increasing doses of chlordiazepoxide and requires further study.

Expression of c-fos in the STLP was inhibited after exposure to novelty, normalized by acute chlordiazepoxide and chronic fluoxetine treatment and correlated with anxiolytic behavioral outcomes. The bed nucleus of the stria terminalis (BST) has been implicated in the expression of fear, stress, and anxiety (Walker et al, 2003). Some findings suggest that the BST is involved in adaptive coping responses to stress (eg Pezuk et al, 2006), while others suggest it manifests the deleterious effects of stress (eg Stout et al, 2000). The present findings support the former, with increased activation of this region predicting a decreased stress response. Discordant findings may relate to discrete subregions of the BST, since few previous studies have distinguished between the many subdivisions of the BST and the present findings were observed only in the lateral division of the posterolateral part of the BST (ie STLP).

Finally, although aAcb activation was not altered by exposure to the novel environment, chronic fluoxetine treatment resulted in a tripling of $\mathrm{c}$-fos expression which was correlated with the anxiolytic outcome of decreased latency to begin feeding. Similar findings were not observed after acute chlordiazepoxide or subchronic fluoxetine treatment. This pattern of activation is of interest as a possible mechanism through which antidepressants uniquely act to treat anxiety and depression. Because of its critical role in reward mechanisms, the Acb and the mesolimbic dopamine reward circuit have long been implicated in symptoms of depression, including anhedonia (Nestler and Carlezon, 2006). Recent deep brain stimulation studies have implicated the Acb in the treatment and incidence of anxiety disorders (Sturm et al, 2003), including obsessive-compulsive disorder (Okun et al, 2007; Shapira et al, 2006; Sturm et al, 2003). However, the results of these studies were varied, with stimulation either inducing panic (Okun et al, 2007; Shapira et al, 2006) or alleviating symptoms (Okun et al, 2007; Sturm et al, 2003). Although these discordant findings are unresolved, they might be explained by the location of the stimulation probes. Recent animal findings have dubbed the more anterior part of the Acb, an hedonic 'hot spot', while the more posterior extent is responsive to aversive stimuli (Pecina et al, 2006). Similarly, previous findings have identified an anteriorposterior gradient within the Acb, with the more posterior extent of the Acb associated with amphetamine (Essman et al, 1993) and conditioned dopamine (Franklin and Druhan, 2000) induced locomotion. Taken together, activation of the most anterior Acb (but not the posterior) following chronic fluoxetine treatment may reflect the recruitment of a brain region that is important to the experience of positive affect, and is not simply a locomotor effect.

Treatment with fluoxetine is known to reduce feeding behavior and body weight so there is the possibility that reduced motivation to feed could influence behavioral effects in the NIH test. Indeed, we have measured decreased body weight in another group of rats treated in the same manner and with the same doses of fluoxetine as those used in the present study (Howard and Lucki, unpublished). However, it is unlikely that changes in motivation to feed account for the observed reductions of anxiety in response to novelty that are produced by chronic fluoxetine treatment. Specifically, rats treated with fluoxetine for 3 days and 28 days demonstrated different effects on the NIH test despite the presense of fluoxetine-induced anorexic effects after either treatment duration. Rats treated chronically with $5 \mathrm{mg} / \mathrm{kg}$ fluoxetine ate more in the home cage and rats treated with $20 \mathrm{mg} / \mathrm{kg}$ ate less in the home cage compared to vehicle-treated rats. Nevertheless, relative intakes and latencies in the NIH test (ie difference scores) demonstrated a clear relationship between fluoxetine dose and anxiety reduction. Finally, reductions of motivation to feed would likely produce increases in latency and reductions of food intake during both home cage and novel cage testing, and this pattern of effects was not observed in the present experiments.

The present data implicate a number of brain regions in the common effects of chronic fluoxetine and chlordiazepoxide using the NIH test. The dCA2 and STLP may represent common pathways for anxiolytic efficacy. The $\mathrm{Cg}$ responded similarly in response to novelty after both effective anxiolytic treatments, but also subchronic fluoxetine, whereas opposing responses to novelty after chronic and subchronic fluoxetine treatment were measured in the Pir. The aAcb could be a unique mediator of fluoxetine's anxiolytic actions. Finally, c-fos responses to novelty were correlated with the behavioral outcomes of effective anxiolytic treatment. Having found patterns of c-fos activation altered by anxiolytic treatments in so few of the many areas studied provides a short list of regional candidates to pursue that may harbor the key changes which allow antidepressants to become effective after chronic treatment. Additional studies determining the identity of the cells activated by novelty in each region would allow the exact neural substrates associated with the response to novelty, and the effects of anxiolytic drugs to be identified.

\section{ACKNOWLEDGEMENTS}

This work was supported by grants from the National Institutes of Mental Health (MH072832-IL and MH40008-RJV), and the National Alliance for Research on Schizophrenia and Depression (NARSAD - AJB).

\section{DISCLOSURE/CONFLICT OF INTEREST}

The authors (AJB, RJV, IL) have no potential conflicts of interest relating to this report and no other conflicts of interest to declare. 


\section{REFERENCES}

Bechtholt AJ, Hill TE, Lucki I (2007). Anxiolytic effect of serotonin depletion in the novelty-induced hypophagia test. Psychopharmacology (Berl) 190: 531-540.

Bell CJ, Hood SD, Nutt DJ (2005). Acute tryptophan depletion. Part II: clinical effects and implications. Aust $N Z J$ Psychiatry 39: 565-574.

Bissiere S, McAllister KH, Olpe HR, Cryan JF (2006). The rostral anterior cingulate cortex modulates depression but not anxiety-related behaviour in the rat. Behav Brain Res 175: 195-199.

Blier P, Habib R, Flament MF (2006). Pharmacotherapies in the management of obsessive-compulsive disorder. Can J Psychiatry 51: $417-430$.

Bodnoff SR, Suranyi-Cadotte B, Aitken DH, Quirion R, Meaney MJ (1988). The effects of chronic antidepressant treatment in an animal model of anxiety. Psychopharmacology (Berl) 95: 298-302.

Bodnoff SR, Suranyi-Cadotte BE, Quirion R, Meaney MJ (1989). Role of the central benzodiazepine receptor system in behavioral habituation to novelty. Behav Neurosci 103: 209-212.

Borsini F, Podhorna J, Marazziti D (2002). Do animal models of anxiety predict anxiolytic-like effects of antidepressants? Psychopharmacology (Berl) 163: 121-141.

Bremner JD (2006). Stress and brain atrophy. CNS Neurol Disord Drug Targets 5: 503-512.

Bremner JD, Vermetten E (2004). Neuroanatomical changes associated with pharmacotherapy in posttraumatic stress disorder. Ann N Y Acad Sci 1032: 154-157.

D'Sa C, Duman RS (2002). Antidepressants and neuroplasticity. Bipolar Disord 4: 183-194.

Dolnak DR (2006). Treating patients for comorbid depression, anxiety disorders, and somatic illnesses. J Am Osteopath Assoc 106: S1-S8.

Dranovsky A, Hen R (2006). Hippocampal neurogenesis: regulation by stress and antidepressants. Biol Psychiatry 59: 1136-1143.

Dulawa SC, Hen R (2005). Recent advances in animal models of chronic antidepressant effects: the novelty-induced hypophagia test. Neurosci Biobehav Rev 29: 771-783.

Dulawa SC, Holick KA, Gundersen B, Hen R (2004). Effects of chronic fluoxetine in animal models of anxiety and depression. Neuropsychopharmacology 29: 1321-1330.

Essman WD, McGonigle P, Lucki I (1993). Anatomical differentiation within the nucleus accumbens of the locomotor stimulatory actions of selective dopamine agonists and d-amphetamine. Psychopharmacology (Berl) 112: 233-241.

Franklin TR, Druhan JP (2000). Expression of Fos-related antigens in the nucleus accumbens and associated regions following exposure to a cocaine-paired environment. Eur J Neurosci 12: 2097-2106.

Gelenberg AJ, Chesen CL (2000). How fast are antidepressants? J Clin Psychiatry 61: 712-721.

Mayberg HS, Brannan SK, Tekell JL, Silva JA, Mahurin RK, McGinnis S et al (2000). Regional metabolic effects of fluoxetine in major depression: serial changes and relationship to clinical response. Biol Psychiatry 48: 830-843.

Mayberg HS, Lozano AM, Voon V, McNeely HE, Seminowicz D, Hamani C et al (2005). Deep brain stimulation for treatmentresistant depression. Neuron 45: 651-660.

Merali Z, Levac C, Anisman H (2003). Validation of a simple, ethologically relevant paradigm for assessing anxiety in mice. Biol Psychiatry 54: 552-565.

Nestler EJ, Carlezon Jr WA (2006). The mesolimbic dopamine reward circuit in depression. Biol Psychiatry 59: 1151-1159.
Nutt D, Argyropoulos S, Hood S, Potokar J (2006). Generalized anxiety disorder: a comorbid disease. Eur Neuropsychopharmacol 16(Suppl 2): S109-S118.

Okun MS, Mann G, Foote KD, Shapira NA, Bowers D, Springer U et al (2007). Deep brain stimulation in the internal capsule and nucleus accumbens region: responses observed during active and sham programming. J Neurol Neurosurg Psychiatry 78: $310-314$.

Paxinos G, Watson C (2004). The Rat Brain in Stereotaxic Coordinates - The New Coronal Set, 5th edn. Elsevier Academic Press: Boston, MA.

Pecina S, Smith KS, Berridge KC (2006). Hedonic hot spots in the brain. Neuroscientist 12: 500-511.

Pezuk P, Goz D, Aksoy A, Canbeyli R (2006). BNST lesions aggravate behavioral despair but do not impair navigational learning in rats. Brain Res Bull 69: 416-421.

Phan KL, Fitzgerald DA, Cortese BM, Seraji-Bozorgzad N, Tancer ME, Moore GJ (2005). Anterior cingulate neurochemistry in social anxiety disorder: $1 \mathrm{H}-\mathrm{MRS}$ at 4 Tesla. Neuroreport 16: 183-186.

Rauch SL, Jenike MA, Alpert NM, Baer L, Breiter HC, Savage CR et al (1994). Regional cerebral blood flow measured during symptom provocation in obsessive-compulsive disorder using oxygen 15-labeled carbon dioxide and positron emission tomography. Arch Gen Psychiatry 51: $62-70$.

Rauch SL, Savage CR, Alpert NM, Miguel EC, Baer L, Breiter HC et al (1995). A positron emission tomographic study of simple phobic symptom provocation. Arch Gen Psychiatry 52: 20-28.

Rauch SL, Shin LM, Segal E, Pitman RK, Carson MA, McMullin K et al (2003). Selectively reduced regional cortical volumes in post-traumatic stress disorder. Neuroreport 14: 913-916.

Roche M, Commons KG, Peoples A, Valentino RJ (2003). Circuitry underlying regulation of the serotonergic system by swim stress. J Neurosci 23: 970-977.

Sanders SK, Shekhar A (1995). Regulation of anxiety by GABAA receptors in the rat amygdala. Pharmacol Biochem Behav 52: 701-706.

Shapira NA, Okun MS, Wint D, Foote KD, Byars JA, Bowers D et al (2006). Panic and fear induced by deep brain stimulation. J Neurol Neurosurg Psychiatry 77: 410-412.

Sheline YI, Gado MH, Kraemer HC (2003). Untreated depression and hippocampal volume loss. Am $J$ Psychiatry 160: 1516-1518.

Stone EA, Lehmann ML, Lin Y, Quartermain D (2006a). Depressive behavior in mice due to immune stimulation is accompanied by reduced neural activity in brain regions involved in positively motivated behavior. Biol Psychiatry 60: 803-811.

Stone EA, Yan L, Ahsan MR, Lehmann ML, Yeretsian J, Quartermain D (2006b). Role of CNS alpha1-adrenoceptor activity in central fos responses to novelty. Synapse 59: 299-307.

Stout SC, Mortas P, Owens MJ, Nemeroff CB, Moreau J (2000). Increased corticotropin-releasing factor concentrations in the bed nucleus of the stria terminalis of anhedonic rats. Eur $J$ Pharmacol 401: 39-46.

Struthers WM, DuPriest A, Runyan J (2005). Habituation reduces novelty-induced FOS expression in the striatum and cingulate cortex. Exp Brain Res 167: 136-140.

Sturm V, Lenartz D, Koulousakis A, Treuer H, Herholz K, Klein JC et al (2003). The nucleus accumbens: a target for deep brain stimulation in obsessive-compulsive- and anxiety-disorders. J Chem Neuroanat 26: 293-299.

Sun W, Park KW, Choe J, Rhyu IJ, Kim IH, Park SK et al (2005). Identification of novel electroconvulsive shock-induced and 
activity-dependent genes in the rat brain. Biochem Biophys Res Commun 327: 848-856.

Walker DL, Toufexis DJ, Davis M (2003). Role of the bed nucleus of the stria terminalis versus the amygdala in fear, stress, and anxiety. Eur J Pharmacol 463: 199-216.

Wang D, Noda Y, Tsunekawa H, Zhou Y, Miyazaki M, Senzaki K et al (2007). Behavioural and neurochemical features of olfactory bulbectomized rats resembling depression with comorbid anxiety. Behav Brain Res 178: 262-273.
Wirtshafter D (2005). Cholinergic involvement in the cortical and hippocampal Fos expression induced in the rat by placement in a novel environment. Brain Res 1051: 57-65.

Wu JC, Buchsbaum M, Bunney Jr WE (2001). Clinical neurochemical implications of sleep deprivation's effects on the anterior cingulate of depressed responders. Neuropsychopharmacology 25: S74-S78.

Zhou L, Huang KX, Kecojevic A, Welsh AM, Koliatsos VE (2006). Evidence that serotonin reuptake modulators increase the density of serotonin innervation in the forebrain. J Neurochem 96: 396-406. 